DEPARTAMENTO DE ZOOTECNIA ESPECIAL E EXTERIOR DOS ANIMAIS DOMESTICOS

Diretor: Prof. Dr. João Soares Veiga

DEPARTAMENTO DE ZOOCTENIA GERAL, GENÉTICA ANIMAL E BROMATOLOGIA

Diretor: Prof. Dr. Milton de Souza Piza.

\title{
PÊSO AO NASCER E CRESCIMENTO PONDERAL DE BOVINOS HOLANDESES PUROS POR CRUZAMENTO NUMA FAZENDA DE CAMPINAS (E. DE S. PAULO)
}

(IIVli WEIGIT OF IIOLSTEIN CROSSBRRED CAIAVS) •

\begin{tabular}{|c|c|c|c|}
\hline João Soares & Veica & $\begin{array}{c}\text { Armando Chichfi } \\
\text { Docente-Iivre }\end{array}$ & $\begin{array}{c}\text { FERN ANDO ANDREASI } \\
\Lambda \text { ssistente }\end{array}$ \\
\hline
\end{tabular}

A criação do gado Holandês tem se desenvolvido muito, nestes últimos anos, em nosso paí. Além das numerosas importaçóes efetuadas por particulares e pelos Govêrnos Federal e dos Estados, procuram, nossos criadores, imprimir novos rumos ao sistema de criar e de explorar essa raça leiteira, oferecendo-lhe melhores condições de trato e serviço mais eficimnte de defesa sanitária.

0 estudo do comportamento dessa raça entre nós, pois, dado seu elevado valor econômico, é de real importância, não só para podermos avaliar seu grau de adaptação, como para podermos julgar os efeitos da alimentação e do trato que, em certas condições, the oferecemos.

O desenvolvimento ponderal dos animais da raça Holandesa, criada no Brasil, tem sido estudada por vários autores e os animais olsservados referem-se, principalmenie, aos criados em estabelecidos oficiais, tais como: -..- Escola Superior de Agricultura "Luís de Queiroz" (") - Estação Experimental de Criação de Pindamonliangaba $\left(^{5}\right)$ e em Minas Gerais ( $\left.{ }^{1}\right)$.

O desenvolvimento ponderal dos animais, muito mais do que outras medidas, como as lineares, está sujeito à influência de inúmeros fatôres genéticos e ambientais e, dentre êstes últimos, a alimentação é, sem dúvida. fator de importância decisiva. O estudo dos pêsos dos animais representa, assim, dado de real valor para o contrôle da criação. E como são vácias as condiçôes de região para região. sobretudo no que se refere à alimeniação ' ao trato, é natural verificarem-se grandes variaçóes de pêso dos animais de diferentes rebanhos, embora pertencentes à mesma raça.

Outros fatûres, que năo a alimentação, tanubém podem influir no desenvolvimento ponderal dos animais e, entre êles, o rlima c as doenças infecciosas e 
parasitárias têm marcada atuação. As babesioses, por exemplo, cobram sério tributo aos bovinos criados em nosso meio, e sua influência, sôbre o desenvolvimento e a capacidade produtiva dos animais, não pode ser subestimada.

\section{MATERIAL E METODO}

Os animais estudados no presente trabalho, de raça Holandesa, puros por cruzamento, foram criados em estabelecimento particular, Fazenda Bôa Vista, de propriedade da Companhia Cafeeira Rio Feio, sob orientação de João de Morais Barros.•

Esse modelar estabelecimento da família Morais Barros dedica-se à criação do gado Holandês, há quase 25 anos, e ao lado de animais puros de origem, selecionam-se produtos puros por cruzamentos. Os touros empregados, sempre foram -animais puros de origem, provenientes da Holanda, ou filhos dêstes, nascidos no Brasil. São animais perfeitamente aclimatados ao anbiente de Campinas, Estado de São Paulo. Presentemente, esta cidade, de clima ameno, reune, talvez, o maior e o melhor núcleo de gado Holandês, variedade preta e branca. do Estado de São Paulo. As vacas da Fazenda Bôa Vista são submeridas, quando em produção, ao regime de meia estabulação, recebendo rações de concentrados e de cana durante todo o ano. Na época do inverno, recebem ainda, silagem de milho. As novilhas e as vacas sêcas, vistoriadas periódicamente, vivem em regime exclusivo de campo, em invernadas de capim gordura (Mclinis minutijlorn). A cobertura é efetuada a curral e a porcentagem de natalidade atinge, em média, de 75 a 78 por cento, estando as parições regu!armente distribuidas por todos os meses do ano.

Ao nascer, são os bezerros retirados das vacas, recebendo o rolosiro, por alguns dias. Posteriormente, alimentam-se com leite integral, proveniente do estábulo, mais ou menos de acôrdo com o pêso (1/7) até a idade de 3-1 meses. Aos três meses, substitui-se o leite integral pelo leile desnatado em pó, ađqquirido no comércio. Por ocasião dessa substituição, os hezerros sĩn habituados a comer rações de concentrados, cuja composição é de farelo de trigo, fino e grosso e mistura mineral, contendo cálcio, fósforo, iodo e sal comum. A ração concentrada é administrada com cana picada. A desmana completa se faz a partir dos seis meses de idade. Os jovens bezerros, embora possuam "hoxes" individuais, até três meses de idade, são soltos pela manhã $\mathrm{em}$ piquete de quicúio (' $e$ nisetum longistylum), a fim de tomarem sol. Após os três meses, são levados a outro local, onde permanecem até a desmama. Recolhidos pela manhã, rerebem o leite, a ração dos concentrados e a cana, e são soltos à tarde. Passam a noite no pasto. Apanham naturalmente os carrapatos e çuando a infestacáo é excessiva são pulverizados com parasiticidas. Sofrem, assim, as babesioses nas primeiras idades e raros são os casos de sintomas graves dessas doenças. 
Todos os bezerros são pesados ao nascer e, daí por diante, semanalmente, aos sábados. fssces pêsos são anotados em fichas especiais, comunicados mensalmente ao escritório central da organização e tôdas as acorrências referentes a doenças ou acidentes são, aí, registradas. Ao atingirem o pêso de 200 quilos, os bezerros dejxam de ser controlados, quanto ao pêso.

Para a elahoração dêste trabalho servimo-nos dos dados referentes às fêmeas, desde o nascimclío até a $26 .^{\text {it }}$ semana de idade ( 6 meses, aproximadamente). 0 pêso dos machos foram apenas estudados por ocasião do nascimento, porque, dado o comércio intenso que a organização mantém de venda de seus produtos masculinos, nem sempre pudemos contar com número razoável para a análise, nas diferentes idades. Foram eliminados, dêste estudo, além dos produtos gêmeos, todos os indivíduos que sofreram afecçóes ou acidentes graves, no transcurso de seu descuvolvimenlo, até os seis meses, e que pudessem perturbar sèriamente seu crescimento. Anotamos, assim, cêrca de 90 fêmeas, distribuidas pelas várias classes organizadas segundo o critério adotado das ordens de parição. Para o pêso ao nascer, o número foi bem maior, pois, anotamos todos os animais nascidos em condicúes consideradas normais.

A pesquisa se resumou em verificar:-

1) O pêso ao nascer dos bezerros do sexo masculino e feminino;

2) O desenvolvimento ponderal das fêmeas da $1 .^{a}$ à $26 .^{x}$ semana de idade;

3) Influência da ordem de parição sôbre o desenvolvimento dos produtos;

4) Os ganhos semanal e diário;

5) A correlação entre o pêso da $1 .^{a}$ semana e o pêso da $26 .^{a}$ semana; e

6) Estudo comparativo entre os nossos dados e os obtidos por outros autores.

\section{RESULTADOS}

1) Pêso an nascer - O exame do jêso ao nascer. referente a 126 machos, demonstrou-nos a média de $35,52 \pm 0,49 \mathrm{~kg}$. Total de 140 fêmeas deu-nos a média de $33.08 \pm 0,4.1 \mathrm{~kg}$ de pếso. A diferença entre essas duas médias de pêso $(2,41 \mathrm{~kg})$ de machos e de fêmeas ao nascer é, estatisticamente, significante $(1=3,81)$.

Entretanto, examinando a média de pêso por ordem de parição, verificamos sòmente ser significante a diferença encontrada entre as médias de pêso dos bezerros machos $c$ fêmeas provenientes de segunda cria $(t=4,06)$. Fm tôdas as outras crias, o pêso dos bezerros, machos e fêmeas, é estatística e pràticamente igual. O quadro l elucida melhor nossas afirmações. 
QUADRO I

Pêso ao nascer de bezerros Holandeses da Fazenda Bôa Vista, segundo a ordem da parição (kg)

\begin{tabular}{|c|c|c|c|c|c|}
\hline Ordem da parição & $\mathbf{M}$ & $c h$ os & $\mathrm{F}$ & $\mathrm{m}$ e a $\mathrm{s}$ & $\mathrm{t}$ \\
\hline 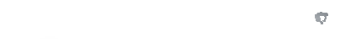 & $\mathbf{n}$ & & $\mathbf{n}$ & & \\
\hline 1. ${ }^{\prime}$ cria $\ldots \ldots \ldots \ldots$ & 38 & $34,58 \pm: 0,81$ & 45 & $32,66 \pm 0,65$ & 1,76 \\
\hline 2." cria . & 32 & 37,48 上 0,94 & 34 & $32,52 \pm 0,79$ & $4,06^{\circ}$ \\
\hline 3." cria $\ldots \ldots$ & 17 & $36,36 \pm 1,02$ & 23 & $34,44=1,33$ & 1,15 \\
\hline $4{ }^{a}$ cria $\ldots$ & 16 & $35,00 \pm 1,85$ & 14 & $35,28 \pm 0,94$ & 0,13 \\
\hline 5. à 8. cria & '23 & 34,16 t土 0,90 & 24 & $32,16 \pm 0,90$ & 1,57 \\
\hline Tôdas as crias .... & 126 & $35,52 \pm 0,49$ & 140 & $33,08 \pm 0,41$ & $3,81^{*}$ \\
\hline
\end{tabular}

* Resultado significante.

O pêso máximo encontrado para bezerros machos, ao nascer, foi de $48 \mathrm{~kg}$ e o mínimo $22 \mathrm{~kg}$. Entre as fêmeas, verificamos amplitude compreendida entre $49 \mathrm{~kg}$ e $21 \mathrm{~kg}$. Pêsos menores que 20 quilos nāo foram levados em consideração, neste estudo.

Examinando, após, a influência das ordens da parição sôbre o pêso dos bezerros, quer machos, quer fêmeas, verificámos que a diferença entre as médias encontradas não ofereceu valor significante, do ponto de vista estatístico. Por outras palavras, não se evidenciou, quer entre machos, quer entre fêmeas, quaisquer diferenças oriundas da ordem da parição. Mesmo ns bezerros nascidos na primeira cria, machos ou fêmeas, não deram diferenças apreciáveis quando comparados com os outros todos somados das crias subseqüentes (Quadros II e III).

\section{QITARRO II}

Análise da variância dos pêsos ao nascer, segunda a ordem da parição | Bezerros machos

\begin{tabular}{|c|c|c|c|c|}
\hline V a r i a c a a & $\begin{array}{r}\text { Graus de } \\
\text { liberdade }\end{array}$ & Quadrados & Variância & $\mathrm{F}$ \\
\hline Total $\ldots \ldots \ldots \ldots \ldots$ & 125 & $3.587,0$ & & \\
\hline Entre crias $\ldots \ldots \ldots \ldots$ & 4 & 194,6 & 48,65 & \\
\hline Dentro crias $\ldots \ldots \ldots \ldots$ & 121 & $3.392,4$ & 28,04 & $1.74 *$ \\
\hline
\end{tabular}

* = Não significativo. 


\section{QUADRO III}

Análise da variância dos pêsos ao nascer, segundo a ordem da parição Bezerros fêmeas

\begin{tabular}{c|c|c|c|c}
\hline V a r i a s $\mathbf{a} . \quad$ & $\begin{array}{c}\text { Graus de } \\
\text { liberdade }\end{array}$ & Quadrados & Variáncia & F \\
\hline Total $\ldots \ldots \ldots \ldots \ldots \ldots$ & 139 & $2.999,0$ & \\
Entre crias $\ldots \ldots \ldots \ldots \ldots$ & 4 & 145,8 & 36,45 & \\
Dentro crias $\ldots \ldots \ldots \ldots$ & 135 & $2.853,2$ & 21,13 & $1,72^{*}$ \\
\hline
\end{tabular}

* = Não significativo.

2) Desenvolvimento ponderal das fêmeas da primeira à vigésima-sexta semana de idade - Noventa fêmeas consideradas normais, por não terem sofrido doenças ou acidentes graves, foram estudadas, quanto ao pêso na primeira semana e nas semanas seguintes. Dessas, foi excluida uma, na 19. semana, por ter sofrido acidente; outra, na $22 .^{\mathrm{a}}$ semana; outra, na $23 .^{\mathrm{a}}$; e mais duas, na $26 .^{\mathrm{a}}$. O quadro IV nos dá idéia do desenvolvimento do pêso dêsses animais e o gráfico I nos proporciona visão esquematizada dêsse cresscimento.

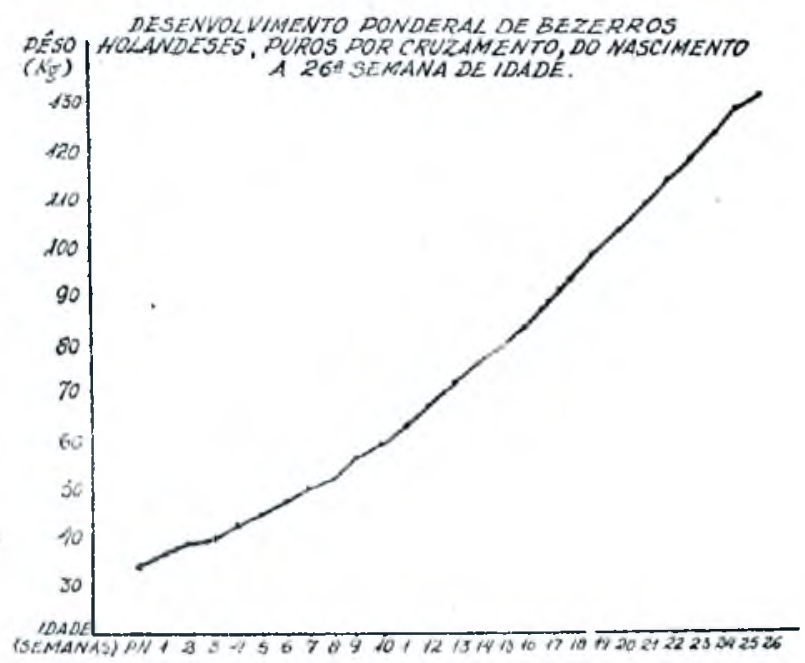




\section{QUADRO IV}

Desenvolvimento ponderal de bezerros Holandeses, puros por cruzamento, da 1.a à 26.a semana de idade

Fêmeas ( $\mathrm{kg})$

\begin{tabular}{|c|c|c|c|c|c|}
\hline Semanas & N.o & M é di a s & $\begin{array}{c}\text { Ganho } \\
\text { semanal }\end{array}$ & $\begin{array}{l}\text { Ganho } \\
\text { diário }\end{array}$ & Observaçöes \\
\hline PN & 90 & $33,34+0,45$ & - & - & \\
\hline 1." & 90 & $35,72 \pm 0,49$ & 2,38 & 0,340 & \\
\hline $2:^{\mathrm{a}}$ & 90 & $37,57 \pm 0,52$ & 1,85 & 0,264 & Pêso ao nascer $=33,34$ \\
\hline 3." & 90 & $39,43 \pm 0,58$ & 1,86 & 0,266 & $\pm 0,45$ \\
\hline $4 .^{\circ}$ & 90 & $41,88 \pm 0,61$ & 2,45 & 0,350 & \\
\hline $5 .^{\mathrm{a}}$ & 90 & $44,30 \pm 0,64$ & 2,42 & 0,346 & \\
\hline $6 .^{n}$ & 90 & $46,88 \pm 0,69$ & 2,58 & 0,369 & \\
\hline $7 .{ }^{2}$ & 90 & $49,99+0,78$ & 3,11 & 0,444 & \\
\hline $8 .^{\mathrm{a}}$ & 90 & $52,90 \pm 0,84$ & 2,91 & 0,416 & \\
\hline $9 .^{\mathrm{a}}$ & 90 & $55,88+0,89$ & 2,98 & 0,426 & \\
\hline $10 .{ }^{\mathrm{a}}$ & 90 & $59,45 \pm 0,95$ & 3,57 & 0,510 & \\
\hline 11." & 90 & $62,72 \pm 1,18$ & 3,27 & 0,467 & \\
\hline 12." & 90 & $67,08 \pm 1,11$ & 4,36 & 0,623 & $\begin{array}{l}\text { Aprox. dôbro do pêso ao } \\
\text { nascer. }\end{array}$ \\
\hline $13 .^{\mathrm{a}}$ & 90 & $70,95 \pm 1,18$ & 3,87 & 0,553 & Aprox. dôbro do pêso da \\
\hline 14. & 90 & $74,79 \mp 1,29$ & 3,84 & 0,549 & 1. ${ }^{\mathrm{a}}$ semana. \\
\hline $15 .^{\circ}$ & 90 & $78,93 \pm 1,37$ & 4,14 & 0,591 & \\
\hline $16 .^{2}$ & 90 & $83,35 \pm 1,49$ & 4,42 & 0,631 & \\
\hline $17 . "$ & 90 & $88,25 \mp 1,53$ & 4,90 & 0,700 & \\
\hline $18 .^{\circ}$ & 90 & $93,18+1,60$ & 4,93 & 0,704 & \\
\hline 19." & 89 & $98,12 \pm 1,73$ & 4,94 & 0,706 & Aprox. 3 vêzes o pêso ao \\
\hline 20. & 89 & $103,02 \pm 1,84$ & 4,90 & 0,700 & nascer. \\
\hline $21 .^{\mathrm{a}}$ & 89 & $107,92 \pm 1,91$ & 4,90 & 0,700 & Aprox. 3 vêzes o pêso da \\
\hline $22 .{ }^{\circ}$ & 88 & $112,58-2,06$ & 4,66 & 0,666 & 1." semana. \\
\hline $23 .^{\circ}$ & 87 & $117,60 \pm 1,97$ & 5,02 & 0,717 & \\
\hline $24 .^{\mathrm{a}}$ & 87 & $122,70 \pm 2,05$ & 5,10 & 0,729 & \\
\hline $25 .^{\circ}$ & 87 & $127,63 \pm 2,09$ & 4,93 & 0,704 & \\
\hline $26 .^{\mathrm{a}}$ & 85 & 131,50 프 2,08 & 3,84 & 0,549 & $\begin{array}{l}\text { Aprox. } 4 \text { vêzes o pêso ao } \\
\text { nascer. }\end{array}$ \\
\hline
\end{tabular}

Com o pêso inicial, ao nascer, igual a 33,34 $\pm 0,45$ (média das 90 fêmeas estudadas para o desenvolvimento), as fêmeas atingem, já na primeira semana, $35,72 \pm 0,49 \mathrm{~kg}$, para terminarem na vigésima-sexta com $131,50 \pm 2,08 \mathrm{~kg}$.

3) Influência da ordem de parição sôbre o desenvolvimento ponderal dos produtos - Procurando investigar se a ordem das parições exerceu alguma influência sôbre o desenvolvimento ponderal dos animais, comparamos, de um lado, os produtos oriundos de primeira cria, e de outro, todos os outros produtos. Essas comparações foram feitas para a primeira, a quinta, a décima, a décima-quinta, a vigésima e a vigésima-quinta semanas. Os resultados das médias dos pêsos, por ordem de parição, estão reunidos no quadro $V$. 
Pêso médio de fêmeas Holandesas, puras por cruzamento, em diferentes idades, segundo a ordem da parição

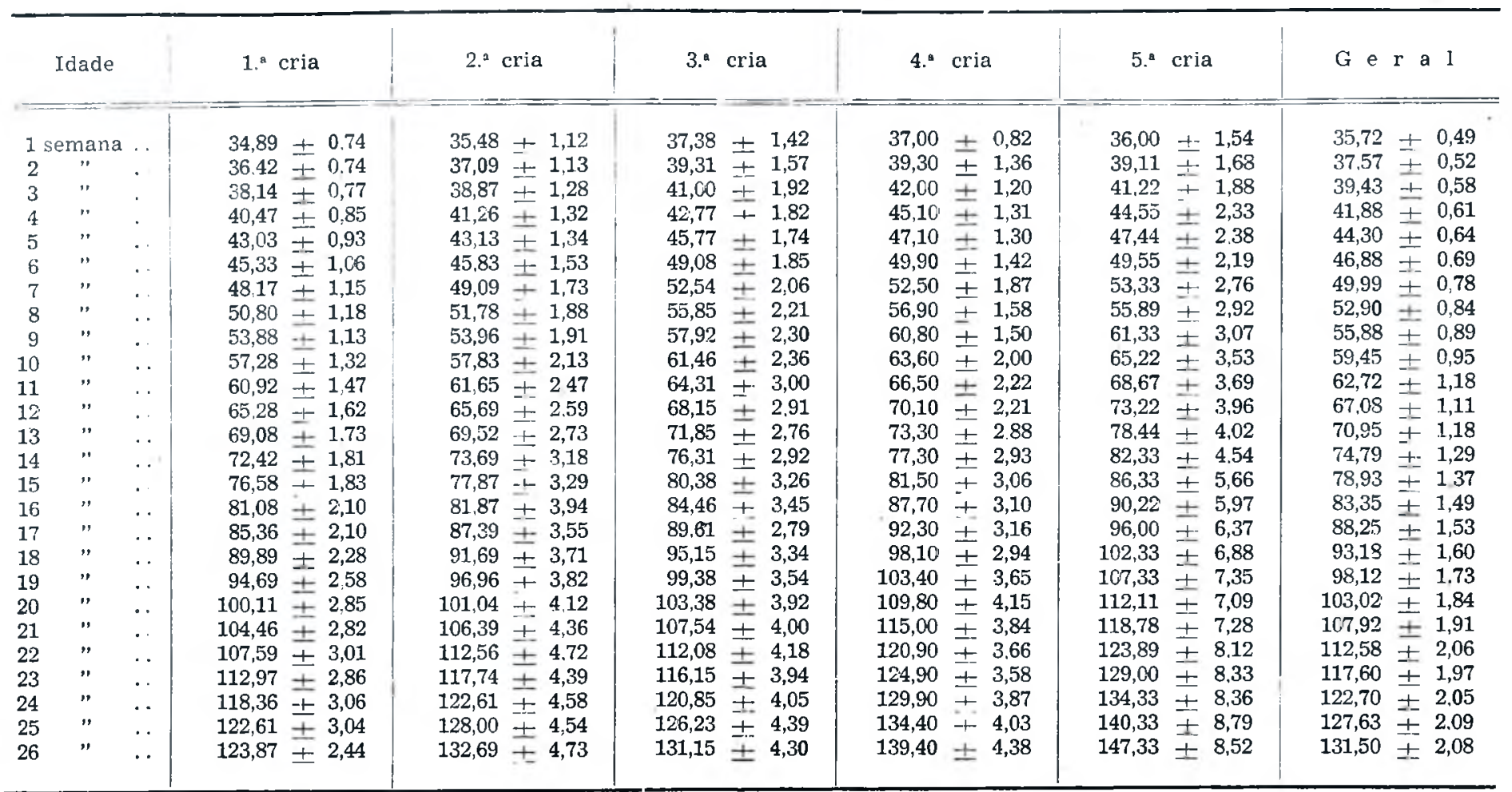

$89,89 \pm 2,28$

$128,00 \pm 4,54$
$+4,73$

As comparações são vistas no quadro VI. 


\section{QUADRO VI}

Comparação entre as médias de pêso de fêmeas Holandesas, puras por cruzamento, oriundas de primeira cria, com fêmeas de outras crias, em diversas idades (kg)

\begin{tabular}{r|r|r|r|r|r|r|r}
\hline Idades & Fêmeas da 1." cria & Fêmeas das outras crias & $\begin{array}{c}\text { Dife- } \\
\text { rença }\end{array}$ & T \\
\hline & & $\mathbf{n}$ & & & & \\
\hline
\end{tabular}

* = Significante $1 \%=2,638$.

Confrontando os bezerros oriundos de diferentes ordens de pariçāo, nas diferentes idades, verificamos, como se vê no quadro VI, que há apenas diferença significativa $(t=3,24)$ entre os pêsos de bezerros nascidos de primeira cria, quando comparados com os de outra cria, na $26{ }^{a}$ semana. Eliminando os produtos de $2 .^{a}$ e $3 .^{p}$ cria, para que se pusesse em confronto animais de idade fisiológica incompleta $(31 / 2-4$ anos), com animais adultos (5 e mais anos), achamos que (quadro VII) essas diferenças são significantes não só na $26 .^{a}$ semana (1\%) como também na $5 .^{\mathrm{a}}$, na $10 .^{\mathrm{a}}$, na $150^{\mathrm{a}}$ e na $20 .^{\mathrm{a}}$ semanas.

\section{QUADRO VII}

Comparação entre as médias de pêso de fêmeas Holandesas, puras por cruzamento, oriundas de primeira cria, com fêmeas das 4. e $5 . .^{a}$ crias

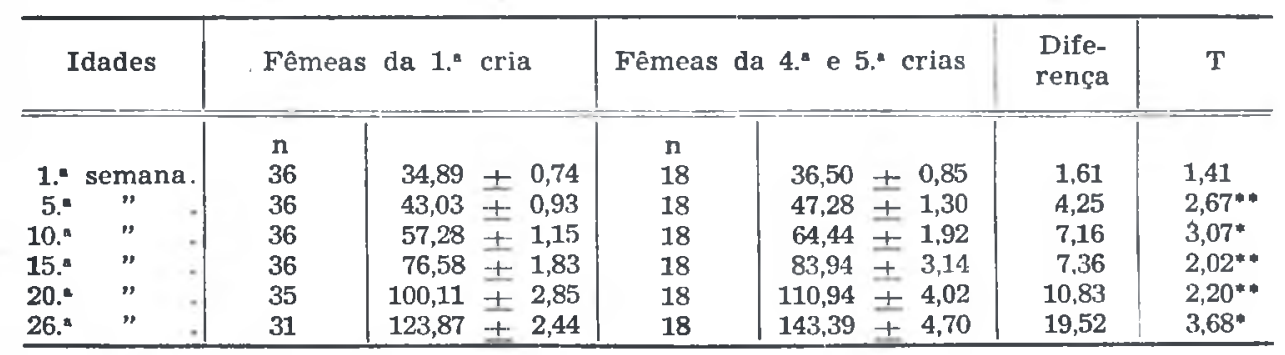

* = Significativo a $1 \%(2,678)$.

* = Significativo a $5 \% \quad(2,008)$

Assim, embora não ficasse demonstrada a influência de ordens de pariçāo sôbre o pêso dos bezerros ao nascer, ela parece existir nas idades mais avançadas. Por outras palavras, embora os bezerros oriundos de vacas de diferentes idades apresentassem pêsos prática e teòricamente iguais ao nascer, com o desenvolvimento através das semanas, parece que os produtos de vacas adultas (mais de 5 anos) ganham mais pêso, a partir da $5 .^{\natural}$ semana, em relação aos produtos de primeira cria (filhos de vacas, com 3 anos). 
4) Ganhos semanal e diário - Os aumentos de pêso, por semana e por dia, poderão ser vistos, em média, no quadro IV. Por êle se verifica que os ganhos vāo aumentando com a idade, havendo, no final, ligeira queda que se nos fôsse dado explicar só poderíamos atribuir ao fato de coincidir, a $26 .^{a}$ semana, com a época da desmama total de alguns animais.

5) Correlação entre os pêsos da primeira semana de idade e na vigésimasexta - Não estabelecemos a correlação entre o pêso ao nascer e a idade final em estudo, mas correlacionamos o pêso na primeira semana e o pêso final, na vigésima-sexta. () resultado dêsse exame deu-nos valor aparentemente baixo ( $\mathrm{r}=$ $0,38)$, porém, estatisticamente significativo. Isto equivale dizer que há correlação posiliva entre o pêso das fêmeas estudadas, observado na primeira semana e - pêso dessas mesmas fêmeas, na $26 .^{\mathrm{a}}$ semana de idade.

6) Estudo comparativo entre nossos dados e os obtidos por outros auto. res - O pêso dos bezerros ao nascer submetidos ao presente estudo é bem menor que o verificado por outros autores $\left({ }^{5}{ }^{6}{ }^{6}\right)$ em rebanhos criados em Piracicaba c em Pindamonhangaba, porém, constituidos de animais puros de origem. Os machos estudados na Escola Superior de Agricultura "Luís de Queiroz" pesaram, em média, $38,42 \pm 0,43 \mathrm{~kg}$ e as fêmeas $36,22 \pm 0.37 \mathrm{~kg}$. Os bezerros da Estação Experimental de Criação de Pindamonhangaba, pesaram, em média, $40,30 \pm 0,60$ os machos e 37,0 $\pm 0,62$ as fêmeas.

As diferenças entre êsses dados e os que ora apresentamos - 2,90 e 3,14 kg para os machos e fêmeas no primeiro caso e 4,78 e 3,92 no segundo caso -- são estatisticamente significativas.

Não podemos, com os dados que possuimos, explicar seguramente a razão dessas diferenças, porém, possivelmente ela deve ser atribuida ao pêso das va. cas, mães dêsses lezerros, consideradas puras por cruzamento e ainda ao sistema de criar adotado na Fazenda, onde os animais perfeitamente adaptados ao clima são criados no regime de campo, recebendo rações suplementares apenas por ocasião da lactação. Vários autores demonstraram a influência materna sôbre o pêso dos bezerros $(4 \in 8)$ ao determinarem as correlaçōes positivas entre pésos das mães e pêsos dos filhos ao nascer. Dawson et al., em $1947\left({ }^{2}\right)$, e VENGE, em 1948 (11), encontraram pêsos ao nascer cada vez mais elevados, à medida que as mães aumentavam de idade, e conseqüentemente, de pêso. $\mathbf{O}$ último autor, porén, achou que o pêso dos produtos é mais influenciado pela idade fisiológica das mães que pelo seu pêso pròpriamente dito. Ele encontrou que, pêso de bezerros oriundos de primeira cria são inferiores, em cêrca de 8 a $12 \%$, aos provenientes de fêmeas de mais de uma parição. 0 pêso ao nascer, segundo KNAl'l et al. $\left({ }^{2}\right)$ é expressão do tamanho, do pêso, da idade e da constituição fisiológica da vaca. 
Entretanto, não podemos discutir tais fatos com os nossos dados. As fêmeas da Fazenda Bôa Vista, são fecundadas, em média, dos dois e meiơ aos três anos de idade, bem desenvolvidas e muito mais tardiamente que as fêmeas de outros rebanhos leiteiros estudados, as quais são fecundadas, geralmente, aos dezesseis e dezoito meses. Talvez resida aí a razão de não encontrarmos diferenças de pêsos decorrentes da ordem de parição, quando comparamos hezerros de primeira cria com bezerros das demais crias.

As diferenças de pêso entre machos e fêmeas ao nascer. bem acentuadas por autores já citados $\left({ }^{5}{ }^{\text {e }}\right.$ ) na raça Holandesa, também as encontramos, quando comparamos tôdas as fêmeas com todos os machos, sem atender à ordem de crias. Considerando, porém, grupos de bezerros por ordem de parição, assinalamos que prática e estatìsticamente, ao nascer, os bezerros machos e fêrneas têm pêsos iguais, com exceção da $2{ }^{a}$ cria, em que a diferença é de $4,90 \mathrm{~kg}$. Não hí motivo nenhum explicável para que isto suceda apenas na $2 a^{a}$ cria, porém, sem dúvida alguma foi essa discrepância que pesou para que a diferença total se mostrasse significativa.

0 desenvolvimento de bezerros da primeira à vigésima-sexla semana, por nós estudado, refere-se apenas aos animais do sexo feminino. Todavia, colocando-se em confronto com os pêsos dos animais puros de origem estudados em nosso meio, verificamos, tal como em relação ao pêso ao nascer que os nossos dados apresentam diferenças geralmente para menos. Essas diferenças, aliás, podem ser vistas no quadro VIII, ao compararmos também com os pêsos referidos por autores americanos $(4,9 \mathrm{e} 10)$, igualmente para animais puros de origem.

\section{QUADRO VIII}

Quadro comparativo entre pêso dos bezerros do sexo feminino (kg)

\begin{tabular}{|c|c|c|c|c|c|c|c|}
\hline $\begin{array}{l}\text { 苋 } \\
\text { 总 }\end{array}$ & 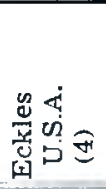 & 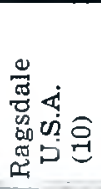 & 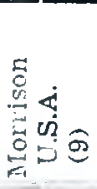 & 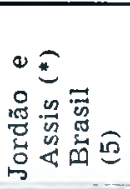 & 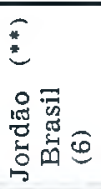 & 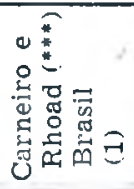 & 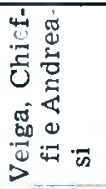 \\
\hline Nasc. & 40.82 & 40,82 & 41,28 & 36,88 & 36,22 & 34,50 & 33,08 \\
\hline 3 meses & 90,72 & 87,54 & - & 103,48 & 100,40 & 93,87 & 70,95 \\
\hline 6 meses & 158,30 & 161,02 & 165,56 & 168,67 & 160,16 & 144,75 & 131,15 \\
\hline
\end{tabular}

* - Estação Experimental de Criação, Pindamonhangaba, São Paulo.

** - Escola Superior de Agricultura "Luís de Queiroz". Piracicaba.

*** - Escola Superior de Agricultura "Viana Nébias Morais".

O quadro VIII demonstra que a diferença entre os "standard" de desenvolvimento fornecidos por vários autores, para animais puros de origem, são hem superiores aos pêsos que encontramos nas diferentes idades. para animais puros 
por cruzamento. O fato de haver já grande diferença com relação ao pêso ao nascer sugere que deve se tratar, de diferenças de pêso das vacas do rebanho em geral. Os hezerros são menores ao nascer e prosseguem menos pesados até os seis meses. E' possível, pois, que no final, quando adultos, tenham êsses animais menor desenvolvimento que os rebanhos comparados. A correlação entre os pêsos ao nascer, aos 3 e aos 6 meses de idade e na idade adulta tem sido assinalado por outros pesquisadores $\left(2^{\mathrm{e}}{ }^{b}\right)$. Correlação entre pêso ao nascer $\mathrm{e}$ pêso aos 6 meses foi também por nós evidenciada, positiva e significativa.

Nunca se deve perder de vista, porém, que fizemos essa comparação a título de curiosidade. Os animais que estudamos, em primeiro lugar, não são "puros de origem" e sim "puros por cruzamento" e, em segundo lugar, não seguem as normas alimentares observadas pelas criações que serviram para têrmo de comparação. Fisses animais - objeto de nossos estudos — são criados se. gundo o sistema adotado na Fazeuda, halituando-se ao regime de campo, is intempéries e ao sol. Seu pêso, aliás, não difere muito dos obtidos por animais "puros de origem", criados em Minas Gerais, com todos os cuidados exigidos (1), sendo de notar-se que os pêsos dados por êstes autores referem-se a machos e fêmeas conjuntamente $\left({ }^{5}\right)$.

\section{SUMARIO E CONICLUSOES}

Num rebanho de gado Holandês composto de animais "puros por cruzamento", foram estudados o pêso ao nascer dos prodıtos masculinos e femininos e o desenvolvimento ponderal das fêmeas da primeira à vigésima-sexta semana de idade. Através dêsse estudo verificou-se que o pêso ao nascer dos animais estudados é igual a $35,52 \pm 0,49 \mathrm{~kg}$ para os machos (126 individuos) e 33,08 $\pm 0,41$ para as fêmeas ( 140 individuos), sendo a diferença entre ambos considerada significaliva. Fstudando as diferenças entre pêsos de machos e de fêmeas por ordem de gestação, verificou-se que apenas entre produtos de segunda cria é que a diferença é significativa, sendo os pêsos dos produtos masculinos e femininos, em outras parições, prática e estatisticamente iguais.

A influência da ordem da parição sôbre o pêso dos bezerros ao nascer, citada por vários autores, não foi evidenciada neste trabalho, isto é, não houve diferença significativa entre o pêso ao nascer de bezerros oriundos da primeira cria, quando comparados com os de outras crias. Entretanto, diferenças significativas foram encontradas, na vigésima-sexta semana, quando se compararam os pêsos de bezerros de primeira cria com os de outras crias $\left(2 .^{a}, 3 .^{a}, 4 .^{a}\right.$ e $\left.5 .^{a}\right)$. Quando essa comparação foi feita entre bezerros de primeira cria e bezerros oriundos de vacas com 1 ou mais crias, as diferenças foram significativas na $5 .^{\mathrm{a}}$, na 10..$^{\mathrm{a}}$, na $15 .^{\mathrm{a}}$ e na $200^{\mathrm{it}}$ semanas, além de o ser na $26 .^{\mathrm{a}}$.

lói enconlrada correlaçáo significaliva direta entre o pêso ao nascer e o pêso de animais aos seis meses de idade. 


\section{SUMMARY AND CONCLUSIONS}

In a herd of crossbreed Holsteins cattle, studies were being carried out in order to observe $\left({ }^{1}\right)$ the birth weight of bulls and heifers, and $\left({ }^{2}\right)$ the ponderal weight of the heifers from the 1st up to 26 th week of age.

From these studies it has been observed, that the weight at the birth of the investigated animals is equal to $35,53 \pm 0,49 \mathrm{~kg}$. for the bulls and $33,08 \pm 0,4 \mathrm{l}$ kg. for the heifers, the differences between them being significant. Studying the differences between males and females weights in successives pregnancies, a significant difference could be verified only among animals of the 2nd calving, no difference being found in successive ones,

In these studies, contrarily to the dates published by other authors, no significant difference between the birth weight of calves from the 1st calving and from successive others was found.

However, significant differences have been shown in the 26th week of age, when comparative studies among the weight of calves from the lst calving and other ones (i.e., 2nd, 3th, 4th, 5th), were made. When these comparative studies have been made among calves from the lst calving and others from cows with four or more calvings, significant differences in the 5th, 10th, 15th, 20th and 26th weeks of age were demonstrated.

A significant correlation between the birth weight and the weight of animals at the age of six months was revealed.

\section{BIBLIOGRAFIA}

I - Carneiro, G. G. e A. O. Riroad - 1935 - Estudo sôbre o desenvolvimento de bezerros. Bol. Agric. Zootec. e Vet., Minas Gerais

2 - Dawson, W. N., R. W. PHir.ips and W. H. Br.ack - 1947 - Birth weight as a criterium of selection in beef cattle. Jour. An. Sci., 6(3) $247-57$

3 - Eckies, C. H. - 1919 - A study of the birth weight of calves. Missouri .Agric. Exp. Sta., Bull. 35

4 - Eckı.es, C. H. - 1939 - Dairy cattle and milk production. 3rd. ed. New York. The Macmillan Co.

5 - Jordão, L. I'. e F. I'. Assis - 1939 - Estudo sôbre o crescimento ponderal de bovinos holandeses. Rev. Ind. Anim., S. Paulo, 2, N.S. (4):6-28

6 - Jonvão, L. P. - 194.1 - Estudo sôbre o crescimento em pêso dos bezerros da raça holandesa, variedade malhada de preto. Bol. Ind. Anim., S. Paulo, 4, N.S. (2):90-104

7 - KNAPP, B. J. - W. V. LAMHERT and W. H. BLACK - 1910 - Factors influencing lenght of gestation and birth weight in cattle. Jour. Ayric. Res., 61:277-85

8 - McCandlisif, A. C. - 1922 - Studies in growth and nutrition of dairy calves. Jour. Dairy Sci, 5:301-20

9 - Morrison, F. 13. - 1936 - Feeds and feeding. 20th ed. Ithaca, The Morrison Publ. Co.

10 - Ragsdale, A. C. - 1934 - Growth standards for dairy cattle. Missouri Agric. Exp. Sta., Bull 336

11 - Venge, O. - 1948 - Influence of different factors on birth weight of calves. Nord. Jordbr. Forskn., (7-8):208-24. “in” An. Breed. Abst., $17(3): 232,1949$ 